\title{
Aortic valve-sparing operation for autograft failure after the Ross procedure
}

\author{
Aschraf El-Essawi, MD, Jochen Sänger, MD, Stefan Ulrich, MD, Ingo Kutschka, MD, and Wolfgang Harringer, MD, \\ Braunschweig, Germany
}

A s the Ross operation is gaining popularity, reinterventions for autograft failure are gaining importance. Patients with this problem are usually younger adults who would be facing lifelong anticoagulation if the autograft were to be replaced with a mechanical conduit. On the other hand, a biologic valve is not a suitable alternative. Because many of these patients have macroscopically normal or nearly normal valve leaflets, a valve-sparing root reimplantation appears most suited to meet their need for a reintervention that would maintain the promised benefits of the initial Ross procedure. These are the lack of a need for anticoagulation, nearly physiologic hemodynamics, and presumed longevity of repair, provided that the long-term results are comparable to those of root reimplantation for aneurysms of the ascending aorta. We report a case of autograft failure 4 years after a Ross operation that was successfully managed by valve-sparing root reimplantation and concomitant leaflet reconstruction.

\section{Clinical Summary}

A 33-year old man who had undergone a Ross operation with a subcoronary implantation technique because of an incompetent bicuspid aortic valve 4 years previously was seen with a moderate to severe insufficiency of the autograft. Follow-up echocardiography had shown signs of progressive volume overload, with a left ventricular diastolic dimension of $62 \mathrm{~mm}$, a left ventricular systolic dimension of $43 \mathrm{~mm}$, and a left atrial dimension of $38 \mathrm{~mm}$, as well as a mild reduction of the ejection fraction $(50 \%)$. The aortic root had a diameter of $35 \mathrm{~mm}$. Clinically, the patient was in New York Heart Association functional class II. Because of his young age and previous Ross operation, the mutual decision (the patient himself was a physician) was for a valve-sparing operation.

Intraoperatively, we found a subcoronary positioned autograft with two tears of $2 \mathrm{~mm}$ at the inflow suture line, which had led to a paravalvular leakage. One tear lay between the right coronary and noncoronary commissures and the other between the right and

\footnotetext{
From the Department of Thoracic and Cardiovascular Surgery, Klinikum Braunschweig, Braunschweig, Germany.

Received for publication June 12, 2005; accepted for publication June 20, 2005.

Address for reprints: Aschraf El-Essawi, MD, Department of Thoracic and Cardiovascular Surgery, Klinikum Braunschweig, Salzdahlumer Strasse 90, 38126 Braunschweig, Germany (E-mail: aelessawi@aol.com).

J Thorac Cardiovasc Surg 2005;130:1215-6

$0022-5223 / \$ 30.00$

Copyright $\odot 2005$ by The American Association for Thoracic Surgery

doi:10.1016/j.jtcvs.2005.06.013
}

left coronary commissures. In addition, there was a minute hole in the base of the left coronary leaflet and a 2-mm long hole close to the free margin of the left coronary leaflet. A valve-sparing procedure (reimplantation technique David I) was performed with a 28-mm Dacron polyester fabric graft and reconstruction of the leaflets with 7-0 interrupted Prolene sutures (Ethicon, Inc, Somerville, NJ). A remaining mild prolapse of the left coronary leaflet was corrected by a triangular plication of the free margin with interrupted 5-0 Prolene sutures. Intraoperative transesophageal echocardiography revealed no residual valve insufficiency and no paravalvular leakage.

The remaining hospital stay was uneventful. The patient was discharged on the sixth postoperative day. At the first follow-up at 1 month, the patient was free of symptoms (New York Heart Association functional class 0 ), with echocardiography showing a left ventricular diastolic dimension of $50 \mathrm{~mm}$, a left ventricular systolic dimension of $36 \mathrm{~mm}$, and an ejection fraction of $60 \%$. The valve was completely competent, and the valve gradient was measured at a mean of $9 \mathrm{~mm} \mathrm{Hg}$. At the last communication at 21 postoperative months, the patient remained symptom free (New York Heart Association functional class 0), and echocardiography showed a stable valve function (aortic insufficiency grade 0-I).

\section{Discussion}

Although short-term results appear to confirm this procedure as a good choice, long-term follow-up in the literature is lacking. Leyh and colleagues ${ }^{1}$ were the first to report on a valve-sparing root reimplantation after a Ross operation because of autograft dilatation and concomitant valve insufficiency. At 14 postoperative months, the autograft showed normal valve function with no signs of regurgitation or stenosis.

Masetti and associates, ${ }^{2}$ reporting on a patient similar to that of Leyh and colleagues ${ }^{1}$ but instead choosing the remodeling technique for sparing the valve, mentioned that their patient was free of symptoms and of regurgitation at 6 months of follow-up. Ishizaka and associates ${ }^{3}$ reported similar results with a similar follow-up in 4 patients in whom they preserved the valve with a root-remodeling technique.

When one considers that the Ross procedure is chosen for its promise of lack of anticoagulation, near-physiologic hemodynamics, and longevity of repair, valve-sparing operations appear wellsuited to a compatible promise at reoperation. This is especially true if long-term outcomes prove to be similar to those seen after valve-sparing operations in patients with aortic aneurysms and aortic regurgitation.

Although the Ross operation has gained popularity, the number of patients undergoing similar reoperative procedures in a single center will remain small for some time. As a result, we see an 
important role of similar case reports in establishing a better understanding of this problem and how best to deal with it.

\section{References}

1. Leyh RG, Kofidis T, Fischer S, Kallenbach K, Harringer W, Haverich

A. Aortic root reimplantation for successful repair of an insufficient pulmonary autograft valve after the Ross procedure. $J$ Thorac Cardiovasc Surg. 2002;124:1048-9.

2. Masetti P, Davila-Roman VA, Kouchoukos NT. Valve-sparing procedure for dilatation of the autologous pulmonary artery and ascending aorta after the Ross operation. Ann Thorac Surg. 2003;76:915-6.

3. Ishizaka T, Devaney EJ, Ramsburgh SR, Suzuki T, Ohye RG, Bove EL. Valve sparing aortic root replacement for dilatation of the pulmonary autograft and aortic regurgitation after the Ross procedure. Ann Thorac Surg. 2003;75:1518-22.

\title{
A giant pleural fibrous tumor
}

\author{
Heyman Luckraz, FRCS, ${ }^{\text {a }}$ Saima Ehsan, MBBS, ${ }^{a}$ Allen R. Gibbs, FRCPath, ${ }^{b}$ and \\ Eric G. Butchart, FRCS, ${ }^{a}$ Cardiff, United Kingdom
}

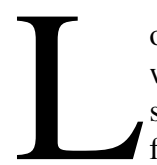
ocalized (solitary) fibrous tumors of the pleura (LFTPs) were first described as a separate entity in $1931,{ }^{1}$ despite having first been reported in $1870 .^{2}$ They represent fewer than $5 \%$ of pleural neoplasms, with a prevalence of approximately 2.8 cases per 100,000 hospital patients. Immunohistochemical analysis has confirmed these tumors to be nonmesothelial in origin. ${ }^{3}$ They arise from either visceral or parietal pleura and may undergo malignant transformation (as many as $12 \%$ of cases). ${ }^{4}$

Symptoms such as dyspnea, cough, chest pain, arthritic pain, finger clubbing, and hypoglycemia (from production of insulinlike growth factors) are present in 50\% of cases, whereas the remainder are discovered incidentally. The heaviest LFTP described to date weighed 1850 g. ${ }^{5}$ We describe a case of an LFTP that enlarged at an average rate of $10 \mathrm{~g} / \mathrm{month}$ during a period of 16 years.

\section{Clinical Summary}

A 67-year-old woman was referred with a left pleural spaceoccupying lesion (Figure 1). She had undergone investigations 16 years before this episode, with an incidental finding of a shadow in the left oblique fissure on chest radiography. Computed tomographic (CT) scan with biopsy favored a diagnosis of loculated fluid collection in the fissure. Unfortunately, the patient was unavailable for follow-up after that, until she was seen recently after development of finger clubbing, mild breathlessness, left-sided chest pain, and dry cough.

\footnotetext{
From the Cardiothoracic Unit and the Histopathology Department, University Hospital of Wales, Cardiff, United Kingdom.

Received for publication Jan 22, 2005; revisions received Feb 22, 2005; accepted for publication April 5, 2005.

Address for reprints: Heyman Luckraz, FRCS, Cardiothoracic Unit, Block C5, University Hospital of Wales, Heath Park, Cardiff CF14 4XN, UK (E-mail: HeymanLuckraz@aol.com).

J Thorac Cardiovasc Surg 2005;130:1216-7

$0022-5223 / \$ 30.00$

Copyright $\odot 2005$ by The American Association for Thoracic Surgery

doi:10.1016/j.jtcvs.2005.04.035
}

The patient had clinical signs of pleural effusion, but a pleural tap was dry. CT revealed a large lesion occupying the left pleural cavity. CT-guided biopsy revealed fibrotic tissue, with multifocal areas of fibroblastic reaction and associated mild lymphohistiocytic perivascular infiltrate. The appearances were considered nondiagnostic. She therefore underwent exploratory left thoracotomy, which revealed a gigantic lobulated mass $(23 \times 20 \times 16 \mathrm{~cm})$, separate from the usual left intrathoracic structures (Figure 2). There were two main vascular pedicles, one arising from the oblique fissure and the other from the pleural surface of the left hemidiaphragm. There were several other minor vascular pedicles. The main vascular pedicles were ligated with nonabsorbable ties (2-0 silk), whereas the minor ones were either ligated or occluded by diathermy. The mass weighed $1998 \mathrm{~g}$.

Macroscopic examination showed a smooth-surfaced, nodular, gray tumor, which on cut section was solid and revealed a gray, yellow, and brown variegated appearance with areas of necrosis. Spindle-shaped cells with hemangiopericytic, patternless, and hyaline areas were identified on histologic examination, in keeping with a diagnosis of solitary fibrous tumor. No features of malignancy were seen on light microscopy, despite extensive sampling. Specifically, mitotic rate was less than 1 per 10 high-power fields.

The patient made an uneventful postoperative recovery. She was discharged home on the sixth postoperative day.

\section{Discussion}

Resection of LFTP represents a small percentage of thoracic surgical activity $(<1 \%)$. Two interesting presenting symptoms of LFTP include finger clubbing and hypoglycemia. Hypertrophic osteoarthropathy is present in a fifth of patients, resulting from abnormal production of hyaluronic acid by tumor cells. ${ }^{5}$ The production of insulinlike growth factor 2 accounts for the hypoglycemic events (4\% of patients) and also impairs the growth hormone counterregulatory response to low blood sugar levels. ${ }^{5}$ These symptoms abate once the lesion has been completely excised.

Chest radiography and CT scanning with contrast remain the investigations of choice for LFTP. Pedunculated tumors show 